\title{
chapter Community Psychiatry: A Work in Progress
}

\author{
Tom K. J. Craig
}

\section{Introduction}

The closure and reprovision of the hospital asylums in the last century led the fundamental transformation of psychiatric services across Europe, North America and Australia. Italy undertook the most radical change, barring admissions to public mental hospitals and replacing inpatient beds with community residential care. ${ }^{1}$ The second fastest decant was in parts of North America where more attention went to closure than reprovision, with consequences of soaring numbers of mentally ill people in prison and of homeless on the streets of several major cities. ${ }^{2}$ The British experience fell somewhere between the two, following a more gradual trajectory, doing quite well with reproviding for the asylum population but in trouble from the outset with how to manage the steady accumulation of new cases with multiple and enduring disabilities stuck on acute wards when transfer to the asylum was no longer possible. This chapter recounts some of the journey, focusing on the experience in England and Wales from 1960 to 2010. The major landmarks of this journey are summarised in Box 30.1.

\section{Box 30.1 Major Landmarks in the Evolution of Community Psychiatry, 1960-2010}

- Launch of asylum closure, 1960-5: Minister of Health Enoch Powell launches plans to replace hospital asylums with 60 beds per 100,000 population located in new district general hospitals (DGHs), with most mental illness managed in the community. ${ }^{3}$ Encouragement from psychiatrists. ${ }^{4}$

- Reconfiguration and aspirations, 1966-75: Generic social work and 'sectorisation' aim at integrated care focused on the same population. Aspirational White Paper Better Services for the Mentally Ill published but stalls in context of NHS reorganisation and political upheaval. ${ }^{5}$

- Expansion of community care but cracks appear, 1976-86: Increased collaborative mental health services in primary care; ${ }^{6}$ first Community Mental Health Centre (CMHC) opens. ${ }^{7}$ Concerns that these developments are at the expense of people with severe mental illness. Health and local authority staff in community and residential services reluctant/unable to manage challenging behaviour and 'new long-stay' patients accumulate. ${ }^{8}$ First asylum closes in 1986.

- Fear and loathing, 1987-96: Asylum closures accelerate with mostly beneficial outcomes for the resettled patients, ${ }^{9}$ but increasing criticism by the public, media and politicians of mental health services' failure to provide adequate supervision for new cases requiring long-term care. ${ }^{10}$ Introduction of care programme approach aimed at providing better management of risk. ${ }^{11}$ NHS 
reorganisation establishes NHS Trusts that are no longer coterminous with local authorities.

- Specialisation of community care, 1997-2010: Fears continue. Mental health staff pulled back to secondary care; National Service Framework (NSF) reconfigures Community Mental Health Teams (CMHTs) to provide assertive outreach $(\mathrm{AO})$, early intervention and crisis resolution home treatment teams, ${ }^{12}$ resulting in considerable service disruption and fragmentation; Mental Health Act revised to include Community Treatment Orders (CTOs). Introduction of IAPT (Improving Access to Psychological Therapies) services increases provision of psychological therapy for common mental disorders. ${ }^{13}$ World economic crisis in 2008 and the subsequent austerity programme fell heavily on social care.

\section{Closing the Asylum}

The impetus for closing the hospital asylum and providing treatment close to where people live came from a combination of optimism, disquiet and financial concerns: optimism among psychiatrists who found that the introduction of social and occupational therapies and the advent of chlorpromazine allowed them to unlock the hospital doors, do away with physical restraint and close long-stay beds, successfully discharging patients to outpatient clinics and day hospitals; ${ }^{14}$ moral outrage at the conditions in some asylums fuelled by empirical findings that many behavioural problems among incarcerated patients were consequences of institutional life; ${ }^{15}$ and, finally, the cost of maintaining the old asylums that became difficult to justify as the model of care was increasingly discredited.

In 1961, the minister of health, Enoch Powell, addressed the National Association of Mental Health at its annual conference, in which he included all these themes and called on psychiatrists and wider health and welfare bodies to provide the variety of community services for people whose needs were 'little short' of what only a hospital could provide (see also Chapter 1). ${ }^{16}$ Anticipating his speech, a report estimated that bed requirements could fall by as much as 70,000 by $1975 .{ }^{17}$ The old asylums would be replaced by a network of district general hospitals (DGHs), each serving a population of around 100,000 with up to 60 beds supported by group homes, day centres and mobile teams, models of which were already emerging around the country. At Warlingham Park, in Surrey, the first community nursing posts were established to support patients discharged from the asylum (see also Chapter 31) ${ }^{18}$ In Manchester, Maurice Silverman described a district service that prioritised outpatient clinics, domiciliary visiting and day care, relying on just 100 inpatient beds for a population of 254,000. Four out of eight psychiatrists in Manchester, each serving a population of approximately 250,000, said they no longer needed the large mental hospital. ${ }^{19}$ In 1968, a reorganisation of social services recommended bringing together all providers of personal social care into new social services departments in local authorities and principles of 'sectorisation' were introduced in which health and social care focused on the same local population.

Powell had estimated a closure and modernisation process lasting fifteen to twenty years but in fact it all took much longer. A great deal of the delay had to do with the worsening economic situation and industrial unrest through the 1970s and 1980s. Successive governments struggled to cope with strikes by coal miners, ambulance drivers, grave diggers and 
refuse collectors. Along the way, a reorganisation of the NHS (amusingly described as written in incomprehensible 'mandarin managerial English') ${ }^{20}$ contributed to the loss of senior managerial posts and amplified disquiet among nursing and medical staff (see also Chapter 12). ${ }^{21}$ Consultants complained that they were being made to do more work with less support; nurses marched in protest over low wages and against private health care; and senior medical staff took medical action, 'working to rule' for almost four months. Somewhat surprisingly, amidst this chaos, Barbara Castle, Labour minister of health, published a White Paper, Better Services for the Mentally $\mathrm{Ill}^{22}{ }^{22}$ setting out a vision for future community mental health care. Economic circumstances meant little of this could be realised. Pioneering studies such as those in Manchester proved difficult to replicate, not least because of the paucity of residential and day care capable of managing challenging behaviours (see also Chapter 26). Local authorities struggled with competing priorities, including improving children's services, while some of the funding allocated to mental health ended up bailing out financial crises in general hospitals. Asylum discharges to that point had largely been of the more able patient, with surveys reporting that several hundred patients identified for discharge remained in hospital. ${ }^{23}$ Furthermore, as the impetus to close the asylums gathered pace, the option to transfer patients from the acute ward to longterm asylum care was cut off. While it was possible to shorten the length of hospitalisation for acute illness and manage some patients in acute day hospitals, ${ }^{24}$ no new treatment had prevented the accumulation of people with persistent illness that now comprised up to a third of people in the new DGH psychiatric facilities, stuck there for a year or longer. ${ }^{25}$

By 1980, asylum reprovision had become the government's top health priority and pressure was put on regions to close and sell off the old hospital sites as the only way to free up resources to fund new community facilities. The first asylum to close was Banstead Hospital in 1986 and thereafter the quickening pace soon became an end in itself. Most closures followed the same 'train and place' approach in which patients practised various aspects of managing life in the community followed by placement in small groups into ordinary houses, accompanied by staff from the asylum who provided supervision at least daily and in some instances up to twenty-four hours. The homes were intended 'for life' then considered a very important reassurance and safeguard. This resettlement process was evaluated in a longitudinal study of the closure of Friern Barnet and Claybury hospitals in north London. ${ }^{26}$ Although patients showed little change in symptoms or behaviour, most preferred being out of hospital and had significant gains in terms of social and domestic skills, social networks and living conditions. Fears that the move might be associated with higher mortality and homelessness were not realised, although 38 per cent had subsequent readmissions with a third of these having very lengthy hospitalisations. Even the small number of patients with challenging behaviours who were initially transferred to secure accommodation on the edge of the old hospital site did well, many moving on to community group homes. ${ }^{27}$

Despite these positive results, there were concerns that employing ex-institutional staff to support patients simply perpetuated institutional practices that could only be solved by bringing in a new workforce not contaminated by history, while the notion of providing a 'home for life' was soon abandoned. On the other hand, there were 'not in my backyard' protests and opposition to resettlement by people anxious about the impact on the values of their properties and of risks to their children. These fears were fuelled by the practice (on grounds of confidentiality but also an attempt to avoid confrontation) of not giving neighbours prior notice before patients were moved to their new homes. An experimental 
programme showed that openness and preparation of neighbours resulted in greater acceptance and integration but came too late to have much effect on policy. ${ }^{28}$ Finally, with hospital closures, many of the occupational and sheltered employment schemes provided by the old asylums also ended and were not replaced, leaving many patients idle and lonely. ${ }^{\text {sup} 29}$

By 1993, just over a quarter of the 130 large asylums in England had closed and beds for mental illness had fallen by two-thirds to $50,278 .^{30}$ Yet pressures on acute inpatient beds continued unabated. Occupancy levels were frequently well above 100 per cent and patients were admitted to private hospitals that had seen the business opportunity and stepped in to plug the gap.

\section{Community Care Takes Off}

As outpatient services developed, some psychiatrists started running clinics in primary care or provided a consultation-liaison service to general practitioners. Some mental health professionals, particularly community psychiatric nurses, were seconded or directly employed in primary care. ${ }^{31}$ Brief psychological therapies for common mental disorders, including counselling and behavioural and cognitive therapies, were increasingly available across professional groups. ${ }^{32}$ Extending support to primary care was popular with general practice and some models had good empirical support, including reductions in hospital admission. ${ }^{33}$ The approach also chimed with views that lay behind asylum closure, notably that mental health care would best progress when delivered in non-institutional, nonstigmatising settings by staff not tainted by the institution.

Later controlled trials confirmed the benefit of these approaches in primary care and, in many respects, were the success story of community mental health. In practice, however, they were overtaken by a different model that was shaped by concerns about failures in the management of severe mental illness. Borrowing a model from the United States, the first Community Mental Health Centre was established in south London with a generous grant from the Gatsby Charitable Foundation. Opened in 1978, the Mental Health Advice Centre (MHAC) comprised a multidisciplinary team based in a deliberately non-descript community location. It provided referral and walk-in access for anyone with mental health problems living in the local catchment area. ${ }^{34}$ The service model was soon replicated elsewhere, with similar centres doubling in number in England every two years and with eighty-one centres open by $1987 .{ }^{35}$ Yet the approach was not without problems. The walk-in service was swamped by people seeking help for problems of daily life, arguably at the expense of severe mental disorders. ${ }^{36}$ A survey of the fate of people with severe mental illness, including those in the catchment area of the MHAC, found half continuing to experience severe symptoms and behavioural problems with, paradoxically, the least wellfunctioning receiving the lowest level of support. ${ }^{37}$

Concerns from politicians, the press and the public about psychiatry's apparent inability to manage risk accelerated through the 1990s as people with severe mental illness became much more visible in the community. Managing severe mental illness in the asylum had been relatively easy. Patients were in one geographical location, moved between the ward and on-site or nearby supervised occupational facilities, and institutionalisation was reflected in compliance with treatment and the asylum regime. It proved much more difficult to keep track of vulnerable patients in the community. There was a conspicuous rise in the number of homeless mentally ill people, attributed by some to the asylum closure 
programme but actually reflecting the revolving door 'new long-stay' population, changes to housing benefit regulations introduced by the Thatcher government and a less widely acknowledged closure of several large direct-access hostels in which many people with chronic mental disorders had long-term shelter. ${ }^{38}$ In 1992, Christopher Clunis, suffering from paranoid schizophrenia and with a long history of repeated admissions, interspersed with poor engagement with outpatient services, stabbed a stranger in the eye, killing him just one of 39 homicides and 240 suicides by severely mentally ill people in the subsequent 3 years (see also Chapters 23 and 27). A report of a confidential inquiry into these tragedies concluded that many might have been prevented if patients had been adequately supervised. Communication failures, confusion about responsibilities and inadequate use of care plans were all cited as contributory factors. ${ }^{39}$ The Department of Health issued guidance establishing the 'care programme approach for people with a mental illness' in which patients in the community had detailed health and social care plans overseen by a named member of a Community Mental Health Team (CMHT). ${ }^{40}$

To cope with the demand, CMHTs revised their offer for common mental disorders, limiting access to people already known to the teams or by formal referral from general practice and pulling back staff working in primary care. Some CMHTs split into two subteams, one focused on assessment and treatment of common mental disorders and the other taking on the care co-ordination role for severe mental illness. Studies confirmed that patients preferred the less stigmatising CMHT over more traditional outpatient clinics, coordination across health and social care was improved and there were reductions in hospitalisation, resulting in lower costs. ${ }^{41}$ In time, the CMHT model expanded to provide specialist services such as in-reach to hostels for the homeless, with this early work leading ultimately to the DH-funded Homeless Mentally Ill Initiative, which established specialist multidisciplinary teams for homeless people, some of which survive to this day (see also Chapter 26). ${ }^{42}$

Yet, despite evidence for the benefit of CMHTs, they still seemed unable to do anything to prevent continuing tragedies among a few patients. The $\mathrm{DH}$ guidance on care coordination was strengthened in 1995 to give the supervising clinician the right to convey people to hospital if necessary. In the meantime, in the United States, one model of coordinated care became hugely influential. This 'Assertive Community Treatment' (ACT), provided 24-hour support, 7 days per week, ensuring that patients were maintained on medication and received appropriate support for daily living. Community members (family but also police and landlords) were given advice and direction on how to support the individual and, where necessary, an individual was helped to leave unhelpful relationships. A clinical trial comparing this approach to usual care proved ACT to be cost-effective, with patients in the experimental arm spending less time in hospital and with better overall clinical and social functioning. ${ }^{43}$ Around the same time, in Australia, another controlled study diverting acute patients from hospital to 24-hour crisis and aftercare support by a community team also showed significant reductions in hospitalisation. ${ }^{44}$ In England, a research team at the Maudsley Hospital attempted to replicate these findings. Patients at the point of an acute admission were randomised to either hospitalisation and routine care or to experimental home-based care with assertive community support. Outcomes over eighteen months were superior in the experimental service, considerably reducing hospital admissions and length of stay, but the positive results were overshadowed by a tragic homicide in the experimental arm and, perhaps for this reason, the study did not achieve the influence it deserved. ${ }^{45}$ Instead, other studies focused on aspects of the ACT model (the 
size of team caseload or recruitment of patients outside of acute crisis) and failed to show comparable benefit. ${ }^{46}$

Alongside these studies, prompted by concerns about whether new community staff had the skills they required for the job, attention was given to training the multidisciplinary team. Most CMHTs included psychologists and other professionals with skills in the delivery of cognitive behavioural therapy (CBT) and other psychological therapies but few of these were developed for the care of severe mental illness. New interventions seemed to offer some hope. These included 'compliance therapy', based on motivational interviewing techniques that in studies had achieved improvements in insight and medication adherence; family interventions that reduced relapse; and CBT for psychosis. Drawing on these, a postgraduate training course, the Thorn nurse training initiative, was established in London and Manchester to equip community psychiatric nurses with specific skills in risk assessment, medication management, family intervention and how to support aspects of daily living. ${ }^{47}$ The principles of the course were taken up in several centres around the UK but, despite some early success, services struggled to maintain these interventions once the supervision and support provided by the training courses were stopped (see also Chapter 19).

\section{The Specialisation of Community Care}

In 1998, Frank Dobson, the then health secretary, responded to continuing public concern about dangerous mentally ill people in the community by saying he would introduce new regulations to increase places in secure units and change the law to give mental health professionals new Community Treatment Orders (CTOs) to enforce treatment and 'sweep the mentally ill off the street'. ${ }^{48}$ At the same time, and at odds with the idea that mental health teams were not being sufficiently proactive, it was increasingly apparent that there were discrepancies in both the incidence and the treatment response for psychotic disorders between black minority ethnic groups and the indigenous white British population. Not only was incidence considerably higher but people from these backgrounds were more likely to be compulsory hospitalised and to access services through the criminal justice system. ${ }^{49}$ There were challenges of bias in the diagnostic judgement of psychiatrists and allegations that the high rates of incarceration and coercion reflected institutional or even frank racism (see also Chapter 35). ${ }^{50}$

In 1999, the DH produced a National Service Framework (NSF) that recommended training psychiatrists in cultural awareness and introduced new specialist teams to better manage risk while reducing reliance on hospitalisation (see also Chapters 10, 23 and 27). ${ }^{51}$ These new teams included assertive outreach (AO) based on ACT principles, 24-hour crisis resolution and home treatment as an alternative to acute hospital admission and dedicated early intervention services (EIS) for first-episode psychosis. At the time of publication of the NSF, there was scant evidence from UK research for any of these services. The NSF arrived with some force behind it. National groups of experts and champions formed to steer implementation and, at a local level, services went through a protracted and disruptive period of reconfiguration. Not only was there the challenge of identifying staff for the new service but it was also blindingly obvious that some kind of generic CMHT provision would have to persist, perhaps comprising those clinicians who, for whatever reason, had not made the cut for a position in one of the new specialist services. 
The new services introduced structural discontinuities in care that were most likely bad for patients. Those with a first episode of psychosis would receive care from the new specialist early intervention team to a maximum of three years before transfer to the CMHT; people who engaged poorly with the CMHT were to be taken over by a specialist AO team but transferred back to the generic CMHT once adherent with treatment; and those in crisis saw different clinicians from those usually involved in their care - all as though the personal relationship developed with a staff member was inconsequential. These services also fuelled an existing trend for psychiatrists to be dedicated to inpatient or community services, radically changing the traditional approach in which patients were under the care of a consultant psychiatrist across both hospital and community. With the greater resource going to managing severe mental illness, CMHTs increasingly offered only time-limited courses of treatment for people with non-psychotic disorders and tried to maintain links with primary care through 'link workers' but, in practice, also focused on the most disabled and troubling patients.

Earlier scepticism about the value of ACT in the UK was reinforced by a controlled trial that failed to show $\mathrm{AO}$ had any advantage in terms of hospitalisation over that achieved by CMHT care, ${ }^{52}$ and a systematic review concluded that well-resourced CMHTs persistently matched AO outcomes in the UK. ${ }^{53}$ Many of the patients that ended up in AO teams had problems with substance abuse in addition to mental ill health. It was hoped that integrating treatments for both disorders within an AO model would be more effective than treatment by separate services but neither this integrated approach nor a much more intensive intervention of combined psychological therapies made any substantial impact on outcomes. ${ }^{54}$ In contrast, EIS did reduce rehospitalisation and improve clinical and social functioning. ${ }^{55}$ Ultimately, AO services disappeared from many parts of the country while EIS expanded albeit with concern that resources were being diverted from long-term care. Establishing the Crisis Resolution teams took longer, often starting with the rather easier task of facilitating discharge rather than the intended but much more challenging task of diverting the acute admission itself. Eventually, however, the model did get going and amassed some evidence in the $\mathrm{UK}^{56}$

By the end of our epoch, the general public were far more accepting of the idea that mental health problems were common, could be spoken about and could be effectively treated. New models for delivering psychosocial help for common mental disorders emerged, notably Improving Access to Psychological Therapies (IAPT), ${ }^{57}$ and for severe mental illness, new models of occupational support (particularly for paid work; see also Chapter 33$)^{58}$ as well as more proactive housing support encouraged progress towards independence, albeit with no evidence by way of controlled clinical trials. ${ }^{59}$

Dobson's proposals for CTOs eventually found their way into law, though in a less draconian form than originally envisaged. Even before their introduction, international research suggested these approaches had little benefit in terms of reduced rates of rehospitalisation or treatment adherence, ${ }^{60}$ a view supported by a later UK study. ${ }^{61}$ The policy also did little to halt a continuing growth in incarceration in forensic and other long-stay secure accommodation. $^{62}$ Involuntary hospitalisation, originally expected to shrink, instead increased with more rather than less use of locked doors and seclusion. ${ }^{63}$ Important efforts to counterbalance coercion by greater involvement of patients in their care, including, for example, early experiments with the use of joint crisis care plans to reduce compulsion, peer support and 'personal recovery', ${ }^{64}$ emerged to be further developed in the subsequent decade. In 2008, an international financial crisis originating in the United States put paid to much further development, particularly in social care. 


\section{Conclusion}

There is little doubt that community care increased the 'reach' of psychiatry to bring effective treatments to much larger numbers of people in the wider population, sometimes at the risk of accusations that it has encouraged inappropriate medicalisation of the woes of everyday life. If that is one concern, the opposite is the accusation that psychiatry still relies too much on hospital care. Closing the asylum did not guarantee the elimination of institutional care, which remained in the longer-stay rehabilitation units and group homes that replaced the asylum. If added to residential forensic care and mentally ill people in prison, it has been argued that there are now as many people in some form of incarceration as there were in the old hospitals. Changes are also seen in the use of acute inpatient care where the rates of involuntary admissions have steadily risen since the mid-1980s, possibly due to reductions in acute beds or to changes in tolerance of risk among community teams. ${ }^{65}$

As noted by some of the earliest commentators, there is very little appetite in health or social care providers to develop to-scale community residential alternatives to hospitals to the extent done in Italy. There have been a few implementations of crisis houses, ${ }^{66}$ but, typically, these have been for special patient groups not considered at particularly high risk or requiring involuntary care, some of whom would not be hospitalised in any event. Challenging behaviour is still viewed as too risky to be managed in community units, not least because of fears of getting hold of a sufficiently rapid and robust response in an emergency, with the result that, to this day, the model has never caught on as a serious alternative to acute hospitalisation. Similarly, while there are some rehabilitation units that can provide secure care, there is a reluctance to expand provision, as they are viewed as perpetuating institutionalisation. If mental health services should proceed, like in Italy, to radically reduce hospital care, it would need to do this 'at scale' with the full backing of authority and increased tolerance of risk. Such a development is yet to emerge.

\section{Key Summary Points}

- The closure of the old hospital asylums in Britain was driven by psychiatric optimism; moral outrage at overcrowding and poor quality of care; and concerns about the cost of maintaining the old buildings. Initial results were promising, and patients discharged from the asylum experienced a better quality of life with few adverse outcomes. At the same time, mental health care became more multidisciplinary and reached out to people with less disabling conditions.

- Problems emerged when the asylums could no longer accept new referrals of people with enduring disability whose needs for care were publicly visible and who were stuck on acute wards. Community residential facilities were unwilling to accept people with challenging behaviours.

- The prevailing social model was one of a progressive movement towards independence that spoke against the provision of long-stay accommodation. This left ambulatory mental health teams to provide intensive support that nevertheless failed to prevent tragedies, including suicide and homicide.

- The media and politicians claimed community care had failed and demanded more powers to enforce treatment. By the end of the epoch, calls for such draconian measures had ameliorated somewhat but the core dilemma of balancing personal independence with the need for care remained unresolved. 


\section{Notes}

1. M. Tansella, D. De Salvia and P. Williams, The Italian psychiatric reform: Some quantitative evidence. Social Psychiatry (1987) 22: 37-48.

2. A. Gralnick, Build a better state hospital: Deinstitutionalization has failed. Hospital and Community Psychiatry (1985) 36: 738-41.

3. J. E. Powell, John Enoch Powell Speech Archive. http://enochpowell.info/wp-content/uploads/Speeche s/1957-1961.pdf.

4. Goffman, Asylums; Powell, John Enoch Powell Speech Archive.

5. Department of Health and Social Security, Better Services for the Mentally Ill, Cmnd 6233. London: HMSO, 1975.

6. M. Balestrieri, P. Williams and G. Wilkinson, Specialist mental health treatment in general practice: A meta analysis. Psychological Medicine (1988) 18: 711-18; P. Tyrer, N. Selvewright and S. Wollerton, General practice psychiatric clinics: Impact on psychiatric services. British Journal of Psychiatry (1984) 145: 15-19; L. Gask, B. Sibbald and F. Creed, Evaluating models of working at the interface between mental health services and primary care. British Journal of Psychiatry (1997) 170: 6-1.

7. D. I. Brough, N. Bouras and J. P. Watson, The Mental Health Advice Centre in Lewisham. Bulletin of the Royal College of Psychiatrists (1983) 7: 82-4.

8. S. A. Mann and N. Cree, 'New' long-stay psychiatric patients: A national sample survey of fifteen mental hospitals in England and Wales 1972/3. Psychological Medicine (1976) 6: 603-16.

9. Team for the Assessment of Psychiatric Services, Preliminary Report on Baseline Data from Friern and Claybury Hospitals. North East Thames Regional Health Authority, 1988; N. Treiman, J. Leff and G. Glover, Outcome of long stay psychiatric patients resettled in the community: Prospective cohort study. British Medical Journal (1999) 319: 13-167; J. Leff and N. Treiman, Long-stay patients discharged from psychiatric hospitals: Social and clinical outcomes after five years in the community. TAPS Project 46. British Journal of Psychiatry (2000) 174: 217-23; N. Treiman and J. Leff, Long-term outcome of long-stay inpatients considered unsuitable to live in the community. TAPS Project 44. British Journal of Psychiatry (2002) 181: 428-32.

10. Department of Health and Social Security, Better Services for the Mentally Ill; Royal College of Psychiatrists, Report of the Confidential Inquiry into Homicides and Suicides by Mentally Ill People. London: Royal College of Psychiatrists, 1996; Department of Health, Caring for People: The Care Programme Approach for People with a Mental Illness Referred to Specialist Mental Health Services. Joint Health/Social Services Circular, C(90) 23/LASSL(90)11. London: Department of Health, 1990; T. Burns, A. Beadsmoore, A. V. Bhat, A. Oliver and C. Mathers, A controlled trial of home-based acute psychiatric services I: Treatment patterns and costs. British Journal of Psychiatry (1993) 163: 49-54; D. Malone, S. Marriott, G. Newton-Howes, S. Simmonds, P. Tyrer and Cochrane Schizophrenia Group, Community mental health teams (CMHTs) for people with severe mental illnesses and disordered personality (Review), Cochrane Database of Systematic Reviews (2007), https://doi.org/10.1002/14651858.CD000270.pub2; P. W. Timms and A. H. Fry, Homelessness and mental illness. Health Trends (1989) 21: 70-1; T. Craig, E. Bayliss, O. Klein, P. Manning and L. Reader, The Homeless Mentally Ill Initiative: An Evaluation of Four Clinical Teams. London: Department of Health, 1995.

11. Department of Health, Caring for People.

12. Department of Health, National Service Framework: Mental Health. London: HMSO,1999.

13. D. M. Clark, R. Layard, R. Smithies, D. Richards, R. Suckling and B. Wright, Improving access to psychological therapy: Initial evaluation of two UK demonstration sites. Behaviour Research and Therapy (2009) 47: 910-20.

14. J. Harper, Out-patient adult psychiatric clinics. British Medical Journal (1959) 1: 357-60.

15. R. Barton, Institutional Neurosis. Bristol: Wright, 1959; E. Goffman, Asylums: Essays on the Social Situation of Mental Patients and Other Inmates. Harmondsworth: Penguin Books, 1961.

16. Powell, John Enoch Powell Speech Archive. 
17. G. C. Tooth and E. M. Brooke, Trends in the mental hospital population and their effect on future planning. Lancet (1961) 1: 710-13.

18. S. Moore, A psychiatric outpatient nursing service. Mental Health (London) (1961) 20: 51-4.

19. M. Silverman, A comprehensive department of psychological medicine: A 12 months review. British Medical Journal (1961) 2: 698-701; S. Smith, Psychiatry in general hospitals: Manchester's integrated scheme. Lancet (1961) 1: 1158-9.

20. A. Paton, Reorganisation: The first year British Medical Journal (1975) 2: 729-39.

21. National Health Service Reorganisation Act. London: HMSO, 1973.

22. Department of Health and Social Security, Better Services for the Mentally Ill.

23. E. Fottrell, R. Peermohamed and R. Kothari, Identification and definition of long-stay mental hospital population. British Medical Journal (1974) 4: 675-7.

24. S. R. Hirsch, S. Platt, A. Knights and A. Weyman, Shortening hospital stay for psychiatric care: Effect on patients and their families. British Medical Journal (1979) 1: 442; F. Creed, P. Mbaya, S. Lancashire,

B. Tomenson, B. Williams and S. Holme, Cost effectiveness of day and inpatient psychiatric treatment. British Medical Journal (1997) 314: 1381-5.

25. Mann and Cree, 'New' long-stay psychiatric patients.

26. Team for the Assessment of Psychiatric Services, Preliminary Report.

27. Treiman, Leff and Glover, Outcome of long stay psychiatric patients resettled in the community; Leff and Treiman, Long-stay patients discharged from psychiatric hospitals; Treiman and Leff, Long-term outcome of long-stay inpatients considered unsuitable to live in the community.

28. G. Wolff, S. Pathare, T. Craig and J. Leff, Community knowledge of mental illness and reaction to mentally ill people. British Journal of Psychiatry (1996) 168: 191-8.

29. E. W. Harley, J. Boardman and T. Craig Friendship in people with schizophrenia: A survey. Social Psychiatry and Psychiatric Epidemiology (2012) 47: 1291-9; D. A. Curson, C. Pantelis, J. Ward and T. R. E. Barnes, Institutionalism and schizophrenia 30 years on: Clinical poverty and the social environment in three British Mental Hospitals in 1960 compared with a fourth in 1990. British Journal of Psychiatry (1992) 160: 230-41.

30. G. Thornicroft and G. Strathdee, How many psychiatric beds? British Medical Journal (1994) 309: 970-1.

31. K. Gournay and J. Brooking, Community psychiatric nurses in primary health care. British Journal of Psychiatry (1994) 165: 231-8.

32. L. Mynors-Wallis, I. Davies, A. Gray, F. Barbour and D. Gath, A randomised controlled trial and cost analysis of problem-solving treatment for emotional disorders given by community nurses in primary care. British Journal of Psychiatry (1997) 170: 113-19; Balestrieri, Williams and Wilkinson, Specialist mental health treatment in general practice.

33. Tyrer, Selvewright and Wollerton, General practice psychiatric clinics; Gask, Sibbald and Creed, Evaluating models.

34. Brough, Bouras and Watson, The Mental Health Advice Centre in Lewisham.

35. E. Sayce, T. K. J. Craig and A. P. Boardman, The development of Community Mental Health Centres in the U.K. Social Psychiatry and Psychiatric Epidemiology (1991) 26: 14-20.

36. Ibid.

37. D. Melzer, A. S. Hale, S. J. Malik, G. A. Hogman and S. Wood, Community care for patients with schizophrenia one year after hospital discharge. British Medical Journal (1991) 303: 1023-6.

38. T. K. J. Craig and P. W. Timms, Out of the wards and onto the streets? Deinstitutionalisation and homelessness in Britain. Journal of Mental Health (1992) 1: 265-75.

39. Royal College of Psychiatrists, Report of the Confidential Inquiry into Homicides and Suicides.

40. Department of Health, Caring for People. 
41. Burns et al., A controlled trial of home-based acute psychiatric services I; Malone et al., Community mental health teams.

42. Timms and Fry, Homelessness and mental illness; Craig, Bayliss, Klein, Manning and Reader, The Homeless Mentally Ill Initiative.

43. L. I. Stein and M. A. Test, Alternative to mental hospital treatment: I. Conceptual model, treatment program and clinical evaluation. Archives of General Psychiatry (1980) 37: 392-7.

44. J. Hoult, I. Reynolds, M. Charbonneau-Powis, P. Weekes and J. Briggs, Psychiatric hospital versus community treatment: The results of a randomised trial. Australian and New Zealand Journal of Psychiatry (1983) 17: 160-7.

45. I. M. Marks, J. Connolly, M. Muijen, B. Audini, G. McNamee and R. E. Lawrence, Home-based versus hospital-based care for people with serious mental illness. British Journal of Psychiatry (1994) 165: 179-94.

46. T. Burns, F. Creed, T. Fahy et al., Intensive versus standard case management for severe psychotic illness: A randomised trial. Lancet (1999) 353: 2185-9; F. Holloway and J. Carson, Intensive case management for the severely mentally ill: Controlled trial. British Journal of Psychiatry (1998) 172: 19-22.

47. S. M. Devane, G. Haddock, S. Lancashire et al., The clinical skills of community psychiatric nurses working with patients who have severe and enduring mental health problems: An empirical analysis. Journal of Advanced Nursing (2001) 27: 253-60; S. Lancashire, J. Haddock, N. Tarrier, I. Baguley, C. Butterworth and C. Brooker, Effects of training in psychosocial intervention for community psychiatric nurses. Psychiatric Services (1997) 48: 39-4.

48. R. Sylvester, Dobson acts to sweep mentally ill off streets. The Independent, 23 October 2011, www .independent.co.uk/news/dobson-acts-to-sweep-mentally-ill-off-streets-1184934.html.

49. G. Harrison, C. Glazebrook, J. Brewin et al., Increased incidence of psychiatric disorders in migrants from the Caribbeans in the United Kingdom. Psychological Medicine (1997) 27: 799-806; G. G. Rwegellera, Differential use of psychiatric services by West Indians, West Africans and English in London. British Journal of Psychiatry (1980) 137: 428-32.

50. F. W. Hickling, K. McKenzie, R. Mullen and R. A. Murray, Jamaican psychiatrist evaluates diagnoses at a London psychiatric hospital. British Journal of Psychiatry (1999) 175: 283-5; S. P. Sashidharan, Institutional racism in British psychiatry. Psychiatric Bulletin (2001) 25: 244-7.

51. Department of Health, National Service Framework.

52. H. Killaspy, P. Bebbington, R. Blizard et al., The REACT study: Randomised evaluation of assertive community treatment in north London. British Medical Journal (2006) 332: 815-20.

53. T. Burns, J. Catty, M. Dash, C. Roberts, A. Lockwood and M. Marshall, Use of intensive case management to reduce time in hospital in people with severe mental illness: Systematic review and meta-regression. British Medical Journal (200) 7: 335-6.

54. S. Johnson, G. Thornicroft, S. Afuwape et al., Effects of training community staff in interventions for substance misuse in dual diagnosis patients with psychosis (COMO study). British Journal of Psychiatry (2007) 191: 451-2; C. Barrowclough, G. Haddock, T. Wykes et al., Integrated motivational interviewing and cognitive behaviour therapy for people with psychosis and comorbid substance misuse: Randomised controlled trial. British Medical Journal (2010) 341: 1-12.

55. T. Craig, P. Garety, P. Power et al., The Lambeth Early Onset (LEO) Team: Randomised controlled trial of the effectiveness of specialised care for early psychosis. British Medical Journal (2004) 329: 1067-70.

56. S. Johnson, F. Nolan, S. Pilling et al. Randomised controlled trial of acute mental health care by a crisis resolution team: The north Islington study. British Medical Journal (2005) 331: 599; G. Glover, G. Arts and K. S. Babu, Crisis resolution/home treatment teams and psychiatric admission rates in England. British Journal of Psychiatry (2006) 189: 441-5.

57. Clark et al., Improving access to psychological therapy.

58. T. Burns, J. Catty, T. Becker et al., The effectiveness of supported employment for people with severe mental illness: A randomised controlled trial. Lancet (1997); 370: 1146-52. 
59. R. Chilvers, G. Macdonald and A. Hayes, Supported housing for people with severe mental disorders. The Cochrane Database of Systematic Reviews, 4: CD000453.

60. R. Churchill, G. Owen, S. Singh et al., International Experience of Using Community Treatment Orders. London: Department of Health, 2007.

61. T. Burns, J. Rugkasa and A. Molodynski et al., Community treatment orders for patients with psychosis (OCTET): A randomised controlled trial. Lancet (2013) 381: 1627-33.

62. S. Priebe, A. Badesconyi, A. Fioritti et al., Re-institutionalisation in mental health care: Comparison of data on service provision from six European countries. British Medical Journal (2005) 330: 123-6.

63. P. Keown, S. Weich, K. S. Bhui and J. Scott, Association between provision of mental illness beds and rate of involuntary admissions in the NHS in England 1988-2008: Ecological study. British Medical Journal (2011) 343: 196-204.

64. On compassion, see K. Sutherby, G. I. Szmukler, A. Halpern et al., A study of 'crisis cards' in a community psychiatric service. Acta Psychiatrica Scandinavica (1999) 100: 56-61; on peer support, see T. Craig,

I. Doherty, R. Jamieson-Craig, A. Boocock and G. Attafua, The consumer-employee as a member of a Mental Health Assertive Outreach Team: I. Clinical and social outcomes. Journal of Mental Health (2004) 13: 59-69; on personal recovery, see M. Slade, Personal Recovery and Mental Illness: A Guide for Mental Health Professionals. Cambridge: Cambridge University Press, 2009.

65. Keown et al., Association between provision of mental illness beds and rate of involuntary admissions.

66. L. Howard, C. Flach, M. Leese et al., Effectiveness and cost-effectiveness of admissions to women's crisis houses compared with traditional psychiatric wards: Pilot patient-preference randomised controlled trial. British Journal of Psychiatry (2010) 197: s32-s40. 